\title{
Sensitivity of Meloidogyne javanica and Tylenchulus semipenetrans to Isothiocyanates in Laboratory Assays
}

\author{
I. A. Zasada and H. Ferris
}

Department of Nematology, University of California, One Shields Avenue, Davis 95616.

Accepted for publication 27 January 2003.

\begin{abstract}
Zasada, I. A., and Ferris, H. 2003. Sensitivity of Meloidogyne javanica and Tylenchulus semipenetrans to isothiocyanates in laboratory assays. Phytopathology 93:747-750.

Isothiocyanates are released through enzymatic degradation of glucosinolates produced by plants in the family Brassicaceae. Glucosinolate profiles differ among plant species and the isothiocyanate derivatives differ in their toxicity to nematodes. Control of plant-parasitic nematodes in soil by isothiocyanates released from incorporated brassicaceous plant material has been inconsistent. Success might be improved with knowledge of the relative toxicities of various isothiocyanates against nema-

against Tylenchulus semipenetrans and Meloidogyne javanica. The $\mathrm{LC}_{90}$ values were 0.01 and $0.03 \mu \mathrm{mol} / \mathrm{ml}$ for 2-phenylethyl isothiocyanate and 0.48 and $0.35 \mu \mathrm{mol} / \mathrm{ml}$ for phenyl isothiocyanate for T. semipenetrans and $M$. javanica, respectively. Brassicaceous sources of benzyl or 2phenylethyl isothiocyanate and, to a lesser extent allyl isothiocyanate, are the most promising candidates for plant-parasitic nematode management. The broader context of this research is the development of approaches for consistent and reliable use of plant-derived chemicals for nematode management. The strategy is to select plants in the family Brassicaceae based on their glucosinolate profiles and the sensitivity of the target nematode species to the associated isothiocyanates.
\end{abstract} todes. Laboratory assays were conducted to determine lethal concentration (LC) values in sand of seven commercially available isothiocyanates

Plants in the family Brassicaceae produce glucosinolates that are thought to function as a defense against insect attack $(5,11,23)$. Glucosinolates are $\beta$-D-thioglucosides distinguished from one another by differences in their organic side chains ( $\mathrm{R}$ groups). Based on these differences, glucosinolates are grouped as either aliphatic, aromatic, or indole forms. They occur in all plant tissues and degrade via enzymatic hydrolysis (1). As a result of tissue damage, the relatively nonreactive glucosinolates come into contact with myrosinase (thioglucoside glucohydrolase, EC 3.2.3.1), which is stored separately in the cell. Hydrolysis yields nitriles, epithionitriles, thiocyanates, and/or isothiocyanates depending on the parent glucosinolate, $\mathrm{pH}$, and other factors (Fig. 1). Isothiocyanates are highly toxic compounds of varying volatility $(8,23)$. They are general biocides whose activity results from irreversible interactions with proteins $(5,24)$.

There is evidence that glucosinolate degradation products are toxic to nematodes. Nematodes were exposed to glucosinolates purified from brassicaceous tissue in the presence or absence of the enzyme myrosinase. With myrosinase present, glucosinolate degradation products were toxic, whereas in the absence of the enzyme intact, glucosinolates were not toxic $(7,9,13,15,17)$.

The products of glucosinolate hydrolysis, assumed to be isothiocyanates, caused differing nematode mortality rates dependent on plant species, cultivar and growth stage (13), chemical composition of the side chain, concentration, and exposure time (17). The isothiocyanate products of the glucosinolates sinigrin, gluconapin, glucotropeolin, and glucodehydroerucin were nematicidal to Heterodera schachtii Schmidt, whereas those from glucoraphenin and sinalbin were not (17). Allyl, benzyl, and 2-phenylethyl isothiocyanates were $100 \%$ lethal to Globodera rostochiensis Wollenweber, but 3-butenyl and 4-methylsulfinyl(butyl) isothiocyanates were less effective (7).

Corresponding author: I. A. Zasada; E-mail address: ZasadaI@ba.ars.usda.gov

Publication no. P-2003-0421-03R

(C) 2003 The American Phytopathological Society
Additional keywords: Brassica hirta, B. juncea, B. napus.

An extensive knowledge base exists regarding glucosinolateproducing brassicaceae species, their enzymatic isothiocyanate products, and their ability to suppress soilborne pathogens $(5,8)$. However, laboratory successes have not always resulted in reliable plant-parasitic nematode management systems in soil. Factors to be considered in extending these studies to practical management systems include, but are not limited to, plant genus and species, plant age, and glucosinolate profile; target nematode species and life stage; and soil properties (5).

Numerous laboratory assays have been conducted to evaluate specific glucosinolates and isothiocyanates for plant-parasitic nematode suppression. Clearly, optimization of brassicaceaebased management systems will require a multilevel experimental approach.

This study represents the first part of a step-wise process that includes laboratory and field experiments. With the knowledge that the toxicity of isothiocyanates is dependent on the structure of the compound and the nematode species being targeted, the objectives of this study were to (i) determine the effect of different concentrations and types of commercially available isothiocyanates against plant-parasitic nematodes and (ii) quantify lethal concentration $\left(\mathrm{LC}_{50}\right.$ and $\left.\mathrm{LC}_{90}\right)$ values of those isothiocyanates that have potential for application as brassicaceous plant material for nematode suppression in soil.

\section{MATERIALS AND METHODS}

Collection of assay nematodes. Mixed stages of Tylenchulus semipenetrans Cobb were extracted by decanting and sieving from soil from an infested olive orchard in Orland, CA. Extracted nematodes were placed on a Baermann funnel and nematodes were collected after $24 \mathrm{~h}$ and used immediately (14). Two-day-old second-stage juvenile Meloidogyne javanica (Treub) Chitwood were obtained from hydroponic tomato cultures (16) and used immediately.

Assay chemicals. Allyl, benzyl, butyl, ethyl, phenyl, 2phenylethyl (Sigma-Aldrich Chemical, St. Louis), and 4-methyl- 
sulfinyl(butyl) (IKT Technologies, Madison, WI) isothiocyanates were tested (Table 1). Purity of all isothiocyanates was at least 97\%. Metham sodium (AMVAC, Los Angeles, CA), a methyl isothiocyanate liberator, was also tested. The formulation of metham sodium was $42 \%$ sodium methyldithiocarbamate (anhydrous) and 58\% inert ingredients. A dilution series of each chemical was prepared in methanol (24) so that the required amount of isothiocyanate was delivered in $50 \mu \mathrm{l}$. Stock solutions were stored in glass containers at $-20^{\circ} \mathrm{C}$.

Assay protocol. Autoclaved silica sand $\left(3.1 \mathrm{~cm}^{3}\right.$; No. 60 silica sand, Corona Industrial Sand, Corona, CA) was weighed into $3-\times$ 2.7-cm polyvinyl chloride (PVC) tubes sealed at one end with a rubber stopper. Approximately 250 to 300 assay nematodes were inoculated on top of the sand in $1 \mathrm{ml}$ of water. A range of known isothiocyanate molarities was added to the tubes. Controls were

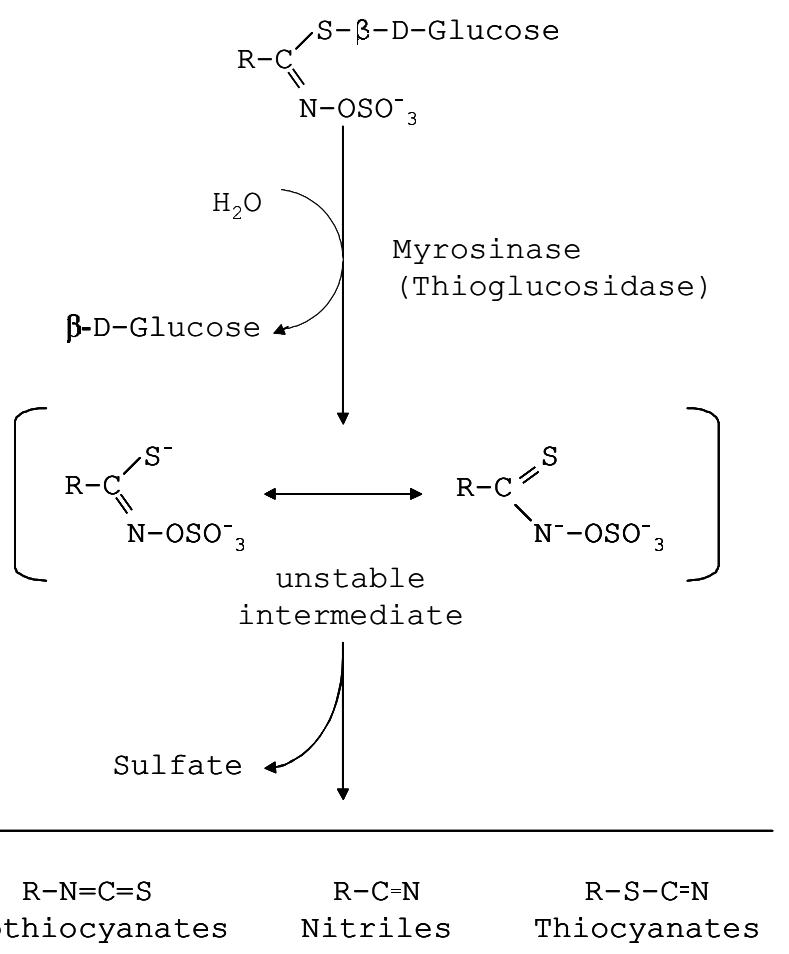

Fig. 1. Enzymatic hydrolysis of glucosinolates via myrosinase. water alone and $50 \mu \mathrm{l}$ of methanol alone. The tubes were sealed with another rubber stopper. The sealed tubes were incubated at $25^{\circ} \mathrm{C}$ for $48 \mathrm{~h}(6,17)$. All isothiocyanate concentrations and controls were completely randomized and replicated five times.

Each isothiocyanate was tested first against $T$. semipenetrans and later against $M$. javanica. In addition to the water alone and $50-\mu l$ methanol controls, a T. semipenetrans control, treated with the calculated $\mathrm{LC}_{50}$ value for each isothiocyanate, was included in the $M$. javanica assays.

After incubation, the rubber stoppers were removed and one end of the PVC tube was covered with a double layer of tissue and placed on a wire mesh screen in a 5-cm petri dish. Surviving nematodes were extracted over $48 \mathrm{~h}$. To evaluate treatment effects, collected nematodes were counted with a dissecting microscope.

Data analysis. All experiments were performed at least twice. The number of nematodes retrieved from the methanol control for each experiment trial was used as the baseline in calculating percent nematode suppression. Values for percent nematode suppression (y) were transformed using a logit transformation, $\ln [y /(1-y)]$, and subjected to regression analysis. LC values were estimated based on the regression. There was no significant interaction of treatments with experimental design $(P<0.05)$ (SAS Institute, Cary, NC). Percent suppression for each isothiocyanate is expressed as the average of at least two trials. LC values are expressed on a soil volume basis.

\section{RESULTS}

There were no differences in nematode survival between the water and methanol controls (data not shown). $\mathrm{LC}_{50}$ and $\mathrm{LC}_{90}$ values were determined for seven isothiocyanates and metham sodium (Table 2). Phenyl isothiocyanate was the least toxic to both nematodes followed by ethyl and butyl isothiocyanates. 2-Phenylethyl isothiocyanate was the most toxic to both nematodes.

Relative toxicities against $T$. semipenetrans for the isothiocyanates tested (in ascending order) were phenyl $<$ (ethyl = butyl) $<$ (metham sodium $=4$-methylsulfinyl(butyl) $=$ allyl $)<(2$-phenylethyl = benzyl). Although the order of toxicity changed for the $\mathrm{LC}_{50}$ and $\mathrm{LC}_{90}$ values, the isothiocyanates always fell into the same distinct toxicity groups.

The isothiocyanate $\mathrm{LC}_{50}$ and $\mathrm{LC}_{90}$ values for $M$. javanica were less consistent than those for $T$. semipenetrans (Table 2). At the $\mathrm{LC}_{50}$ level, butyl, phenyl, and 4-methylsulfinyl(butyl) isothiocyanates were the least toxic to $M$. javanica, whereas 2-phenylethyl

TABLE 1. Isothiocyanate, origin, structure, molecular weight, and common name of parent glucosinolate tested ${ }^{\mathrm{a}}$

\begin{tabular}{|c|c|c|c|c|c|}
\hline Isothiocyanate & Plant species & Plant part & Structure of side chain $\mathrm{R}$ & $\begin{array}{c}\text { Molecular } \\
\text { weight }\end{array}$ & $\begin{array}{l}\text { Glucosinolate } \\
\text { common name }\end{array}$ \\
\hline Allyl & $\begin{array}{c}\text { Armoracia lapathifolia, Brassica } \\
\text { juncea, B. napus, B. oleraceae }\end{array}$ & Seed, leaf, root, stem & $\mathrm{CH} 2(\mathrm{CH})_{2}$ & 99.2 & Sinigrin \\
\hline Benzyl & $\begin{array}{l}\text { Carica papaya, } B . \text { hirta, } \\
\text { Lepidium sativum }\end{array}$ & Seed, leaf, root, stem & $\mathrm{CH}_{2}$ & 149.2 & Glucotropeolin \\
\hline Butyl & A. lapathifolia, Capparis flexuosa & Seed, leaf, root, stem & $\mathrm{CH}_{2}(\mathrm{CH})_{2} \mathrm{CH}_{3}$ & 115.2 & \\
\hline Ethyl & Lepidium menziesi & Seed & $\mathrm{CH}$ & 87.1 & Glucolepdiin \\
\hline Methyl & Capparis spp. & Seed & & 73.1 & Glucocapparin \\
\hline Phenyl & A. lapathifolia & & & 135.2 & \\
\hline 4-Methylsulfinyl(butyl) & B. oleraeae & Seed, leaf, root, stem & $\mathrm{CH}_{2}(\mathrm{CH})_{3}-\mathrm{S}-\mathrm{CH}_{3}$ & 177.3 & Glucoraphanin \\
\hline 2-Phenylethyl & $\begin{array}{l}\text { A. lapathifolia, B. juncea, B. } \\
\text { napus, B. hirta }\end{array}$ & Seed, leaf, root, stem & $\mathrm{CH}_{2}$ & 163.2 & Gluconasturtiin \\
\hline
\end{tabular}

a Data from Fahey et al. (11) and Brown and Morra (5). 
isothiocyanate was the most toxic. At the $\mathrm{LC}_{90}$ level, butyl, 4methylsulfinyl(butyl), phenyl, and ethyl isothiocyanates were the least toxic to $M$. javanica. The ascending order of relative toxicities of the most toxic isothiocyanates at the $\mathrm{LC}_{90}$ level was metham sodium $<$ benzyl $<2$-phenylethyl.

4-Methylsulfinyl(butyl) was the only isothiocyanate tested that differed greatly in its relative order of toxicity against the two nematodes. For $T$. semipenetrans, 4-methylsulfinyl(butyl) was always grouped in the second most toxic group with metham sodium. For $M$. javanica, 4-methylsulfinyl(butyl) was less toxic compared with most of the isothiocyanates tested (Table 2).

The $\mathrm{LC}_{50}$ and $\mathrm{LC}_{90}$ values for ethyl and phenyl isothiocyanates and for metham sodium were not different for the two nematodes. For allyl, benzyl, butyl, 2-phenylethyl, and 4-methylsulfinyl(butyl) isothiocyanates, the $\mathrm{LC}_{50}$ and $\mathrm{LC}_{90}$ values were always lower for $T$. semipenetrans than $M$. javanica (Table 2). The $\mathrm{LC}_{50}$ values ranged from 2 times (butyl) to 15 times (benzyl and 4-methylsulfinyl(butyl)) lower for $T$. semipenetrans. The $\mathrm{LC}_{90}$ values of the tested isothiocyanates ranged from 1.75 times (butyl) to 10 times (4-methylsulfinyl(butyl)) lower for $T$. semipenetrans than for $M$. javanica.

The relative toxicity of individual isothiocyanates was different for each nematode. Benzyl, one of the most toxic isothiocyanates to $T$. semipenetrans, was 50 to 100 times more toxic than phenyl, the least toxic isothiocyanate tested. For $M$. javanica, the difference between the most toxic, 2-phenylethyl, and least toxic isothiocyanate, butyl, was only 10 - to 15 -fold.

Two examples of isothiocyanate response curves for the assay nematodes are presented in Figure 2. The response curve for phenyl isothiocyanate was not different for the two species. There was a difference in the response of $T$. semipenetrans and $M$. javanica to 2-phenylethyl isothiocyanate.

\section{DISCUSSION}

There was a wide range in toxicity among the isothiocyanates, with some 100 times more toxic than others. Relatively slight structural differences can confer profoundly different nematicidal effects, confirming that biological activity is a function not only of the concentration of the product but also of the chemical properties of the R side chain (17).

For both plant-parasitic nematodes tested, there was no clear relationship between structure or molecular weight of the isothiocyanates and their toxicities (Tables 1 and 2). Isothiocyanate toxicity is reported to increase with increasing volatility and decreasing molecular weight $(18,19)$. Higher molecular weight isothiocyanates were less toxic in headspace experiments due to their lower volatility, but were more toxic than the lower molecular weight isothiocyanates when dissolved in agar (24). In our studies in sand, two of the highest molecular weight isothiocyanates, benzyl and 2-phenylethyl, were the most toxic to both nematodes. Our experimental design, with limited headspace, may have favored the higher molecular weight isothiocyanates.
Aliphatic isothiocyanates are expected to be more toxic to a range of organisms than aromatic isothiocyanates $(3,18)$. In our study, aromatic isothiocyanates were the most toxic to both nematode species. Our results are similar to those of Sarwar et al. (24) who found that aromatic isothiocyanates were more toxic to soilborne fungal pathogens than aliphatic isothiocyanates when dissolved in agar.

The use of commercially available isothiocyanates allows direct determination of $\mathrm{LC}_{50}$ and $\mathrm{LC}_{90}$ values by eliminating glucosinolate to isothiocyanate conversion and the possible presence of other alternative breakdown products (e.g., nitriles and epithionitriles) (Fig. 1). The types of assay systems used to determine isothiocyanate LC values vary greatly $(9,20,24)$ but reveal general trends. Our $\mathrm{LC}_{50}$ values for allyl isothiocyanate were several orders of magnitude lower than the $\mathrm{LC}_{50}$ value reported in a solution assay for pure allyl isothiocyanate against Caenorhabditis elegans Dougherty and Nigon (9). The open system used by Donkin et al. (9) may have allowed greater volatilization of allyl isothiocyanate than in ours. Our $\mathrm{LC}_{90}$ value for allyl isothiocyanate for T. semipenetrans was similar to the concentrations of allyl isothiocyanate lethal to five fungal pathogens (24). These concentrations were several orders of magnitude lower than our allyl isothiocyanate $\mathrm{LC}_{90}$ value for $M$. javanica.
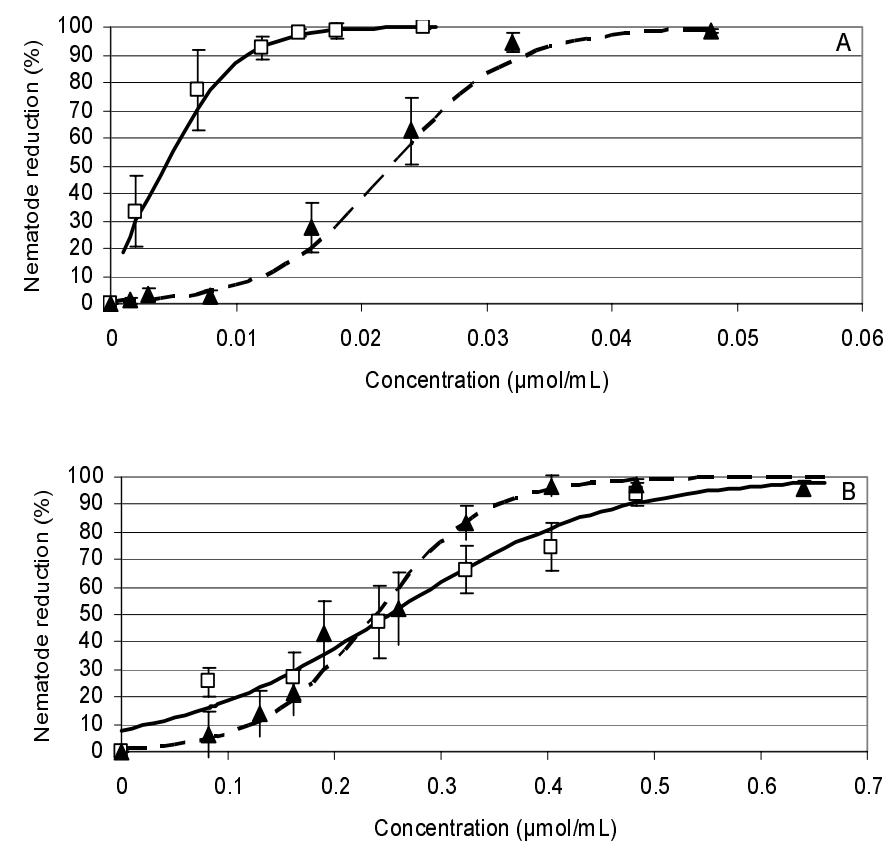

Fig. 2. Response curves for percent reduction of Meloidogyne javanica $(\mathbf{\Delta})$ and Tylenchulus semipenetrans $(\square)$ exposed to concentration ranges of $\mathbf{A}, 2-$ phenylethyl and $\mathbf{B}$, phenyl isothiocyanates. Vertical bars represent the $95 \%$ confidence interval for each mean.

TABLE 2. Lethal concentrations values at 50 and $90 \%\left(\mathrm{LC}_{50}\right.$ and $\left.\mathrm{LC}_{90}\right)(\mu \mathrm{mol} / \mathrm{ml})$ for Tylenchulus semipenetrans and Meloidogyne javanica for commercially available isothiocyanates ${ }^{\mathrm{a}}$

\begin{tabular}{|c|c|c|c|c|}
\hline \multirow[b]{2}{*}{ Isothiocyanate } & \multicolumn{2}{|c|}{ T. semipenetrans } & \multicolumn{2}{|c|}{ M. javanica } \\
\hline & $\mathrm{LC}_{50}$ & $\mathrm{LC}_{90}$ & $\mathrm{LC}_{50}$ & $\mathrm{LC}_{90}$ \\
\hline Allyl & $0.02(0.02-0.03)$ & $0.04(0.03-0.05)$ & $0.10(0.06-0.14)$ & $0.29(0.22-0.35)$ \\
\hline Benzyl & $>0.01(>0.01->0.01)$ & $0.02(>0.01-0.02)$ & $0.04(0.03-0.05)$ & $0.06(0.05-0.07)$ \\
\hline Ethyl & $0.14(0.11-0.18)$ & $0.23(0.19-0.28)$ & $0.11(0.05-0.18)$ & $0.31(0.22-0.42)$ \\
\hline Phenyl & $0.25(0.19-0.34)$ & $0.48(0.38-0.6)$ & $0.24(0.19-0.30)$ & $0.35(0.30-0.42)$ \\
\hline 2-Phenylethyl & $>0.01(>0.01-0.01)$ & $0.01(0.01-0.01)$ & $0.02(0.02-0.03)$ & $0.03(0.03-0.04)$ \\
\hline
\end{tabular}

a All data was $\ln (y /[1-y])$ transformed and subjected to linear regression to obtain $\mathrm{LC}_{50}$ and $\mathrm{LC}_{90}$ values. Values in parentheses indicate $95 \%$ confidence intervals. Intervals overlapping within rows and columns are not significantly different. 
For 2-phenylethyl isothiocyanate, the reported $\mathrm{LC}_{50}$ value, using a different assay system, for Pratylenchus neglectus Rensch (20) was several orders of magnitude greater than our $\mathrm{LC}_{50}$ values for both nematodes. The UC mix (50/50 mix of peat and sand) used by Potter et al. (20) may have absorbed more 2-phenylethyl isothiocyanate because of its higher organic matter content (6).

There were no differences between the LC values for metham sodium against the nematodes. Metham sodium is a broad-spectrum fumigant (12) and might be expected to affect both species similarly. Metham sodium results are not directly comparable to pure methyl isothiocyanate because conversion rates were not determined.

Tylenchulus semipenetrans was more sensitive than $M$. javanica to most of the tested isothiocyanates. Such differences in sensitivity of nematodes have been reported for C. elegans and Xiphinema americanum Cobb (13). Allyl, 2-phenylethyl, and 4-methylsulfinyl(butyl) isothiocyanates are derived from glucosinolates that occur in a variety of brassicaceae (Table 1). The lower sensitivity of $M$. javanica to these isothiocyanates may be related to the wide host range and distribution of this species. Meloidogyne javanica parasitizes over 770 plant hosts, of which Brassica oleraceae L. and B. rapa L. are hosts (21). Tylenchulus semipenetrans has only five hosts including grape and citrus (22). Due to the close association of $M$. javanica populations with some brassicaceae, the nematode may have evolved the ability to withstand plant defense mechanisms.

Isothiocyanates with small LC values and a steep slope are the most toxic (13) (Fig. 2). 2-Phenylethyl isothiocyanate has no effect on $M$. javanica at the $\mathrm{LC}_{90}$ value for $T$. semipenetrans. Relative sensitivity measurements provide a basis for targeting specific nematode species.

This research demonstrates that only some species of brassicaceae are appropriate for plant-parasitic nematode management systems. Those species that contain benzyl or 2-phenylethyl isothiocyanates are effective against both $T$. semipenetrans and $M$. javanica (Table 1). Plants that should be evaluated include $B$. hirta Moench, which contains glucotropeolin and gluconasturtiin, the glucosinolate precursors to benzyl and 2-phenylethyl isothiocyanates, respectively, and B. napus L. or B. juncea (L.) Czern., both containing gluconasturtiin (11). Sinigrin-containing plants (the glucosinolate precursor to allyl isothiocyanate) warrant consideration for $T$. semipenetrans suppression although they may be less effective against $M$. javanica. Brassica juncea and B. napus contain significant concentrations of sinigrin (11).

To achieve consistent and reliable nematode suppression, sufficient brassicaceous material must be applied to provide toxic concentrations of appropriate isothiocyanates. The following is an application example. A high 2-phenylethyl isothiocyanate producing plant, B. napus 'Dwarf Essex', contains approximately $20 \mu \mathrm{mol}$ glucosinolate per g dry wt (10). The $\mathrm{LC}_{90}$ value for $M$. javanica of $0.03 \mu \mathrm{mol} / \mathrm{ml}$ of soil, assuming an equimolar conversion of glucosinolate to isothiocyanate, requires 2.4 dry t/ha of $B$. napus 'Dwarf Essex'. Actual conversion of glucosinolates to isothiocyanates can range from 10 to $60 \%$ (2) depending on chemical structure and environmental conditions (4). At $10 \%$ conversion to 2-phenylethyl isothiocyanate, $24 \mathrm{dry}$ t/ha of the B. napus material would have to be applied to achieve the $\mathrm{LC}_{90}$.

Studies with fall-planted Brassica spp. at the University of California, Davis (I. A. Zasada, unpublished data), demonstrate that the biomass needed to apply 24 dry t/ha of B. napus can be produced on a hectare of land in California.

In summary, our study emphasizes the need to evaluate specific isothiocyanates against specific target organisms. The seven isothiocyanates tested varied greatly in their toxicity toward the two nematode species. The use of a sand assay system allowed for the rapid and reproducible determination of LC values and for the potential to extend this information to a soil environment. The data allow selection of species of brassicaceae containing glucosi- nolate precursors of the most toxic isothiocyanates. The plant material can then be applied based on isothiocyanate LC values.

\section{ACKNOWLEDGMENTS}

We thank E. Hurt and C. Gleason for technical assistance.

\section{LITERATURE CITED}

1. Bjorkman, R. 1976. Properties and function of plant myrosinases. Pages 191-205 in: The Biology and Chemistry of the Cruciferae. J. G. Vaughan, A. J. MacLeod, and B. M. G. Jones, eds. Academic Press, London.

2. Borek, V., Elberson, L. R., McCaffrey, J. P., and Morra, M. J. 1997. Toxicity of rapeseed meal and methyl isothiocyanate to larvae of the black vine weevil (Coleoptera: Curculionidae). J. Econ. Entomol. 90:109-112.

3. Borek, V., Elberson, L. R., McCaffrey, J. P., and Morra, M. J. 1998. Toxicity of isothiocyanates produced by glucosinolates in Brassicaceae species to black vine weevil eggs. J. Agric. Food Chem. 46:5318-5323.

4. Brown, P. D., and Morra, M. J. 1996. Hydrolysis products of glucosinolates in Brassica napus tissues as inhibitors of seed germination. Plant Soil 181:307-316.

5. Brown, P. D., and Morra, M. J. 1997. Control of soil-borne plant pests using glucosinolate-containing plants. Adv. Agron. 61:167-231.

6. Brown, P. D., Morra, M. J., McCaffrey, J. P., Auld, D. L., and Williams, L., III. 1991. Allelochemicals produced during glucosinolate degradation in soil. J. Chem. Ecol. 17:2021-2034.

7. Buskov, S., Serra, B., Rosa, E., Sorensen, H., and Sorensen, J. C. 2002. Effects of intact glucosinolates and products produced from glucosinolates in myrosinase-catalyzed hydrolysis on the potato cyst nematode (Globodera rostochiensis Cv. Woll). J. Agric. Food Chem. 50:690-695.

8. Chew, F. S. 1988. Biological effects of glucosinolates. Pages 151-181 in: Biologically Active Natural Products: Potential Use in Agriculture. H. G. Cutler, ed. American Chemical Society, Washington, D.C.

9. Donkin, S. G., Eiteman, M. A., and Williams, P. L. 1995. Toxicity of glucosinolates and their enzymatic decomposition products to Caenorhabditis elegans. J. Nematol. 27:258-262.

10. Eberlein, C. V., Morra, M. J., Guttieri, M. J., Brown, P. D., and Brown, J. 1998. Glucosinolate production by five field-grown Brassica napus cultivars used as green manures. Weed Technol. 12:712-718.

11. Fahey, J. W., Zalcmann, A. T., and Talalay, P. 2001. The chemical diversity and distribution of glucosinolates and isothiocyanates among plants. Phytochemistry 56:5-51.

12. Gerstl, Z., Mingelgrin, U., and Yaron, B. 1977. Behavior of Vapam (metham-sodium) and methylisothiocyanate (MIT) in soils. Soil Sci. Soc. Am. J. 41:545-548.

13. Halbrendt, J. M., and Jing, G. 1994. Nematode suppressive rotation crops for orchard renovation. Acta Hortic. 363:49-56.

14. Ingham, R. E. 1994. Nematodes. Pages 459-490 in: Methods of Soil Analysis, Part 2. Microbiological and Biochemical Properties. Soil Soc. Am. Book Ser. No. 5, Madison, WI.

15. Jing, G. N., and Halbrendt, J. M. 1994. Nematicidal compounds from rapeseed (Brassica napus and B. campestris). J. Penn. Acad. Sci. 68:29-33.

16. Lambert, K. N., Tedford, E. C., Caswell, E. P., and Williamson, V. M. 1992. A system for continuous production of root-knot nematodes in hydroponic culture. Phytopathology 82:512-515.

17. Lazzeri, L., Tacconi, R., and Palmieri, S. 1993. In vitro activity of some glucosinolates and their reaction products toward a population of the nematode Heterodera schachtii. J. Agric. Food Chem. 41:825-829.

18. Lewis, J. A., and Papvizas, G. C. 1971. Effect of sulfur-containing compounds and vapors from cabbage decomposition on Aphanomyces euteiches. Phytopathology 61:208-214.

19. Munnecke, D. E., and Martin, J. P. 1964. Release of methylisothiocyanate from soils treated with mylone (3,5-dimethyl-tetrahydro-1,2,5,2Hthiadiazine-2-thione). Phytopathology 54:941-945.

20. Potter, M. J., Davies, K., and Rathjen, A. J. 1998. Suppressive impact of glucosinolates in Brassica vegetative tissues on root lesion nematode Pratylenchus neglectus. J. Chem. Ecol. 24:67-80.

21. Potter, J. W., and Olthof, T. H. A. 1993. Nematode pests of vegetable crops. Pages 171-207 in: Plant Parasitic Nematodes in Temperate Agriculture. K. Evans, D. L. Trudgill, and J. M. Webster, eds. CAB International, Wallingford, UK.

22. Raski, D. J. 1991. Tylenchulidae in agricultural soils. Pages 776-777 in: Manual of Agricultural Nematology. W. R. Nickle, ed. Marcel Dekker Inc., New York.

23. Rosa, E. A. S., Heaney, R. K., Fenwick, G. R., and Portas, C. A. M. 1997. Glucosinolates in crop plants. Hortic. Rev. 19:99-125.

24. Sarwar, M., Kirkegaard, J. A., Wong, P. T. W., and Desmarchelier, J. M. 1998. Biofumigation potential of brassicas: III. In vitro toxicity of isothiocyanates to soil-borne fungal pathogens. Plant Soil 201:103-112. 